\title{
A Review of Corrosion and Hydrogen Diffusion Behaviors of High Strength Pipe Steel in Sour Environment
}

\author{
Sung Jin Kim*,† and Kyoo Young Kim** \\ *POSCO Steel Solution Center, Geidong-Dong, Pohang 790-704 Korea \\ **GIFT, Pohang University of Science and Technology (POSTECH), Pohang 790-784, Korea
}

†Corresponding author : sce7@posco.com

(Received October 17, 2014 ; Revised October 21, 2014 ; Accepted October 23, 2014)

\begin{abstract}
A brief overview is given of the corrosion and hydrogen diffusion behaviors of high strength pipe steel in sour environment. Firstly, hydrogen adsorption and diffusion mechanism of the pipe steel is introduced. Secondly, the effect of iron sulfide film precipitated as a result of the corrosion reaction on the steel surface on hydrogen reduction reaction and subsequent hydrogen permeation through the steel is discussed. Moreover, the hydrogen diffusion behavior of the pipe steel under tensile stress in both elastic and plastic ranges is reviewed based on a number of experimental permeation data and theoretical models describing the hydrogen diffusion and trapping phenomena in the steel. It is hoped that this paper will result in significant academic contributions in the field of corrosion and hydrogen related problems of the pipe steel used in sour environment.
\end{abstract}

Key Words : Pipe steel, Corrosion, Hydrogen diffusion, Hydrogen assisted cracking, Tensile stress, Sour environment.

\section{Introduction}

The hydrogen atom is the smallest in diameter among the elements and it is readily adsorbed on the steel surface and diffuse into the steel matrix. It is generally known that the hydrogen atom introduced in the steel diffuses through the interstitial lattice of tetrahedral/octahedral sites $^{1)}$. Most commercial steels, however, contain a variety of metallurgical defects and imperfections such as dislocation, grain boundary, interface between steel matrix and precipitate/inclusion etc $^{2)}$. Due to higher energy state of the defects, hydrogen atom can be preferentially trapped at those sites reversibly or irreversibly. This process leads to significantly lower the mechanical properties such as ductility and/or fracture toughness, often resulting in hydrogen assisted cracking (HAC) failure ${ }^{3,4)}$. Especially, the ferritic steels used in the petrochemical industry such as linepipe steel or pressure vessel steel suffer frequently from the cracking problem when they are used in a sour environment containing $\mathrm{H}_{2} \mathrm{~S}^{5)}$. It is known that atomic hydrogen which results from the reduction of $\mathrm{H}^{+}$ions dissociated from $\mathrm{H}_{2} \mathrm{~S}$ becomes the hydrogen molecule by the recombination reaction $\left(\mathrm{H}+\mathrm{H} \rightarrow \mathrm{H}_{2}\right)$. Since $\mathrm{H}_{2} \mathrm{~S}$ dissolved in aqueous environment suppresses this recombination reaction, the hydrogen atoms are easily adsorbed on the steel surface and diffuse into the steel matrix, which makes the steel more vulnerable to the HAC. The HAC problem can be classified into two categories depending on the source of hydrogen and stress level; one is hydrogen induced cracking (HIC) occurring under no applied stress ${ }^{5,6)}$ and the other is sulfide stress cracking (SSC) occurring under applied tensile stress or residual stress ${ }^{7,8)}$. Especially, the HAC phenomenon appear predo- 
minantly in the weld joint due mainly to the tensile residual stress caused by the thermal expansion and contraction in the weldment during the welding process. The stress developed in a weld joint depends strongly upon the thickness, yield strength (YS) and geometry of the weld ${ }^{9)}$.

With the HAC problem, the decrease in steel wall thickness caused by the anodic dissolution of the steel in sour environment has been one of the major issues for the development of sour-resistant pipe steel. Particularly, the iron sulfide film precipitated as a result of corrosion reaction on the steel surface affects critically the hydrogen evolution rate and subsequent hydrogen diffusion into the steel matrix ${ }^{4)}$.

In the present paper, a brief overview of hydrogen adsorption and diffusion in the steel in sour environment is firstly introduced. Then, the effect of iron sulfide film precipitated on the steel surface on corrosion and subsequent hydrogen diffusion behaviors is discussed. Moreover, the hydrogen diffusion behavior of the pipe steel under tensile stress in both elastic and plastic ranges is explored based on a number of hydrogen permeation test results. With the experimental demonstrations, numerous theoretical models describing the hydrogen diffusion and trapping phenomena in the steel are also briefly reviewed in this paper.

\section{Corrosion and hydrogen diffusion mechanism}

\subsection{Hydrogen adsorption mechanism in sour environment}

The introduction of hydrogen into the steel is resulted from the adsorption of atomic hydrogen which is reduced from $\mathrm{H}^{+}$ion dissociated from $\mathrm{H}_{2} \mathrm{~S}$. For the reduction of $\mathrm{H}^{+}$ion, the following electrochemical corrosion reactions are involved ${ }^{10)}$.

Anodic dissolution of steel: $\mathrm{Fe} \rightarrow \mathrm{Fe}^{2+}+\mathrm{e}^{-}$

Cathodic reaction of hydrogen reduction:

$\mathrm{H}^{+}+\mathrm{e}^{-} \rightarrow \mathrm{H}$

Since atomic hydrogen formed by the reduction reaction is thermodynamically unstable, it tends to become the hydrogen molecule as soon as possible by the recombination reaction $(\mathrm{H}+\mathrm{H} \rightarrow$ $\mathrm{H}_{2}$ ). However, $\mathrm{H}_{2} \mathrm{~S}$ dissolved in aqueous environment suppresses effectively the recombination reaction and consequently, the hydrogen atoms are easily adsorbed on the steel surface and diffuse into the steel matrix ${ }^{2)}$. In fact, the significant increase in hydrogen concentration of steels in sour environment has been demonstrated experimentally by numerous researchers ${ }^{2,5,8)}$. However, there have been a number of mechanistic proposals of the enhancement of hydrogen adsorption and introduction in steels due to the poisoning effect by $\mathrm{H}_{2} \mathrm{~S}^{11-14)}$. In 1965, Bockris et al. ${ }^{11)}$ and Bolmer et al. ${ }^{12)}$ have proposed the poisoning models. In 1974, Iofa et al. ${ }^{13)}$ have developed the mechanism of hydrogen entry as follows:

$$
\begin{aligned}
& \text { Step 1: } \mathrm{H}_{2} \mathrm{~S} \rightarrow \mathrm{H}^{+}+\mathrm{HS}^{-} \\
& \text {Step 2: } \mathrm{HS}^{-} \rightarrow \mathrm{HS}_{\mathrm{ads}}{ }^{-} \\
& \text {Step 3: } \mathrm{HS}_{\mathrm{ads}}{ }^{-}+\mathrm{H}_{3} \mathrm{O}^{+} \rightarrow\left(\mathrm{H}^{-} \mathrm{S}^{-}\right)_{\mathrm{ads}}+\mathrm{H}_{2} \mathrm{O} \\
& \text { Step 4: }\left(\mathrm{H}^{-} \mathrm{S}^{-} \mathrm{H}\right)_{\mathrm{ads}}+\mathrm{e}^{-} \rightarrow \mathrm{HS}_{\mathrm{ads}}{ }^{-}+\mathrm{H}_{\mathrm{ads}}
\end{aligned}
$$

However, their interpretations have been evaluated as incomplete approach because of unknown reaction parameters. Moreover, there is much higher concentration of $\mathrm{H}_{2} \mathrm{~S}$ compared to $\mathrm{HS}^{-}$in acid environment due to much lower solubility of $\mathrm{H}_{2} \mathrm{~S}$. In 1976, Kawashima et al. ${ }^{14)}$ have proposed the following reaction model applicable in acidic solution

$$
\begin{aligned}
& \text { Step 1: } \mathrm{H}_{2} \mathrm{~S}_{\mathrm{ads}}+\mathrm{e}^{-} \rightarrow \mathrm{H}_{2} \mathrm{~S}_{\mathrm{ads}}{ }^{-} \\
& \text {Step 2: } \mathrm{H}^{+} \rightarrow \mathrm{H}_{\mathrm{ads}}{ }^{+} \\
& \text {Step 3: } \mathrm{H}_{2} \mathrm{~S}_{\mathrm{ads}}{ }^{-}+\mathrm{H}_{\mathrm{ads}}{ }^{+} \rightarrow \mathrm{H}_{2} \mathrm{~S} \sim \mathrm{H}_{\mathrm{ads}} \text { (unstable) } \\
& \text { Step 4: } \mathrm{H}_{2} \mathrm{~S} \sim \mathrm{H}_{\mathrm{ads}} \rightarrow \mathrm{H}_{2} \mathrm{~S}_{\mathrm{ads}}+\mathrm{H}_{\mathrm{ads}}
\end{aligned}
$$

The electrical attraction between $\mathrm{H}_{2} \mathrm{~S}_{\text {ads }}{ }^{-}$formed by the Step 1 and $\mathrm{H}_{\text {ads }}{ }^{+}$formed by the Step 2 generates a complex compound of $\mathrm{H}_{2} \mathrm{~S} \sim \mathrm{H}_{\text {ads }}$. Since the compound tends to unstable, it is easily dissociated and consequently, adsorbed hydrogen atom is formed. Fig. 1 shows a schematic illustration of hydrogen adsorption mechanism in sour environment. These mechanisms are well known in the field of sour corrosion occurring in a variety of steels used for linepipe, process pipe and pressure vessel. 


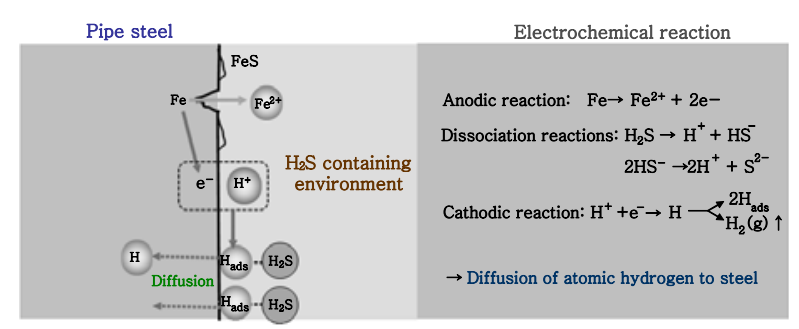

Fig. 1 Hydrogen adsorption and diffusion mechanism of pipe steel in sour environment

\subsection{Sour corrosion and corrosion products}

With the depletion of high quality resources in oil and gas industry, the fraction of $\mathrm{H}_{2} \mathrm{~S}$ gas is increased and as a result of that, the reduction in steel wall thickness caused by the anodic dissolution of the steel in sour environment becomes more serious engineering problem. To mitigate the problems, considerable efforts have been made to modify the composition of the steel, optimize the microstructure and reduce the inclusion/precipitate level in the steel. According to Kim et al. ${ }^{4}$, the iron sulfide $\left(\mathrm{FeS}_{\mathrm{x}}\right)$ film naturally precipitated as a result of corrosion reaction on the steel surface affects critically the hydrogen evolution rate and subsequent hydrogen diffusion into the steel matrix. Since the sulfides $\left(\mathrm{FeS}_{1-\mathrm{x}}, \mathrm{FeS}\right.$ and $\left.\mathrm{FeS}_{2}\right)$ have a good electric conductivity ${ }^{15,16)}$, they act not only as a barrier against the hydrogen diffusion but also as sites for the hydrogen reduction reaction. Particularly, $\mathrm{FeS}_{1-\mathrm{x}}$ forming in the initial stage has a lot of defects which make it porous film. Thus, high interfacial area of the porous sulfide film with high electric conductivity provides a lot of sites for the hydrogen reduction reaction. This behavior has been experimentally demonstrated utilizing both potentiodynamic polarization and hydrogen permeation measurements ${ }^{4}$. Fig. 2 shows the potentiodynamic polarization curves and the morphology of the iron sulfide film on the pressure vessel steel with the increase in immersion time in $\mathrm{H}_{2} \mathrm{~S}$-saturated NACE solution ${ }^{17}$. The figure clearly indicates that both cathodic reaction of hydrogen reduction and average roughness value $\left(r_{a}\right)$ increase with increasing the immersion time. It suggests that the sulfide

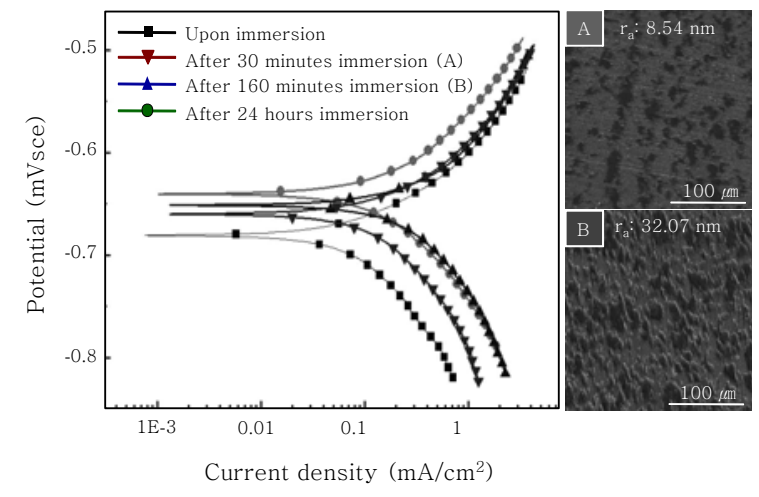

Fig. 2 Potentiodynamic polarization curves of the pressure vessel steel with increasing the immersion time in $\mathrm{H} 2 \mathrm{~S}$ saturated NACE TM0284-96A solution. The SEM images show the surface morphology of the sulfide film formed in the NACE solution ${ }^{4)}$ and the

film with a rougher surface provides a larger interfacial area for the cathodic reaction associated with hydrogen reduction reaction.

It is known that the alloying element of $\mathrm{Cu}$ has a beneficial effect on the corrosion and HIC resistance of the steel used in sour environment ${ }^{18-20)}$. Particularly, Inagaki et al. ${ }^{18)}$ have investigated the influence of $\mathrm{Cu}$ on hydrogen diffusion and HIC resistance in terms of the characteristics of iron sulfide $\left(\mathrm{FeS}_{\mathrm{x}}\right)$ scale formed on the steel surface. Carneiro et al. ${ }^{19)}$ have also indicated that $\mathrm{Cu}$ promotes the formation of a protective film of the type $(\mathrm{Fe} \mathrm{Cu}) \mathrm{S}$ on the steel surface, which suppresses the hydrogen reduction reaction. On the other hand, Blondeau et al. ${ }^{20)}$ have suggested an alternative mechanism and they have reported that $\mathrm{Cu}$ accelerates the recombination of hydrogen atom to molecular hydrogen, resulting in the decrease in hydrogen activity.

In the case of the effect of $\mathrm{Ni}$ on sour corrosion or HAC, it has not been clarified yet. Some literatures underline the adverse effect of $\mathrm{Ni}$ on SSC resistance of the steel $^{21}$, whereas a beneficial effect ${ }^{22)}$ or no effect ${ }^{23)}$ of $\mathrm{Ni}$ have also been indicated. Considering these facts, there have been some contradictory results about the influence of the alloying element such as $\mathrm{Cu}$ and $\mathrm{Ni}$ on sour corrosion and HAC phenomena in the steel. For these reasons, Kim et al. ${ }^{10)}$ have tried to perform the quantitative and fundamental analysis on the effect of $\mathrm{Cu}$ and $\mathrm{Ni}$ 


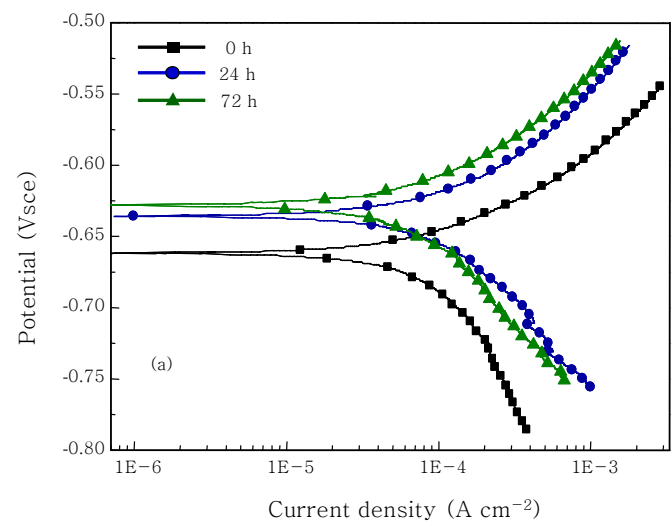

(a)

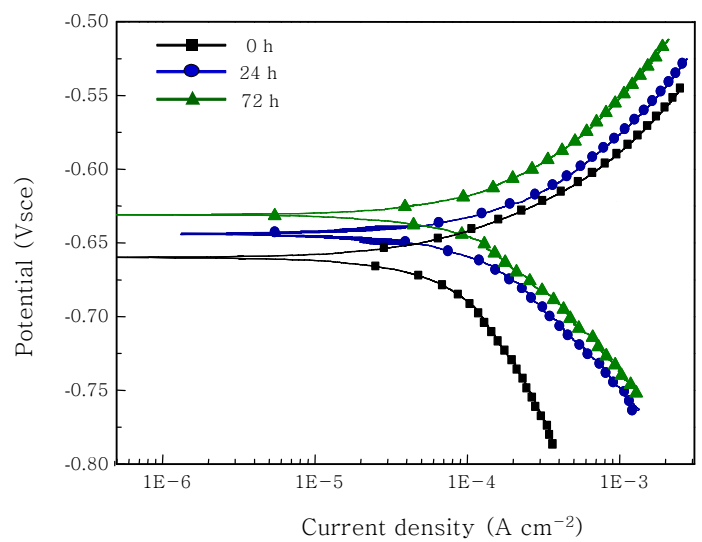

(b)

Fig. 3 Potentiodynamic polarization behavior of the pressure vessel steels with immersion time in NACE solution; (a) $\mathrm{Cu}-\mathrm{Ni}$ bearing steel and (b) Conventional steel

on the sour corrosion behavior in terms of characteristics of the sulfide film. According to them, $\mathrm{Cu}$ and $\mathrm{Ni}$ bearing steel exhibits lower anodic current density and higher polarization resistance than only smaller Ni bearing steel. However, the cathodic current density of the steels increases with the immersion time up to 24 hours. These behaviors are closely associated with the characteristics of the sulfide film formed on the steel surface. The polarization behavior and cross-sectional morphology of the sulfide film formed on the steel surface can be identified in Fig. 3 and Fig. 4, respectively. From the Fig. 4 , it is known that the sulfide film formed on the $\mathrm{Cu}$ and $\mathrm{Ni}$ bearing steel has smaller cracks and defects than that on the only smaller $\mathrm{Ni}$ bearing steel. EDS analysis also indicates that the protective nature of the sulfide film formed on the $\mathrm{Cu}$ and $\mathrm{Ni}$ bearing steel is attributed to the presence of $\mathrm{Cu}$ and $\mathrm{Ni}$ in the sulfide film.
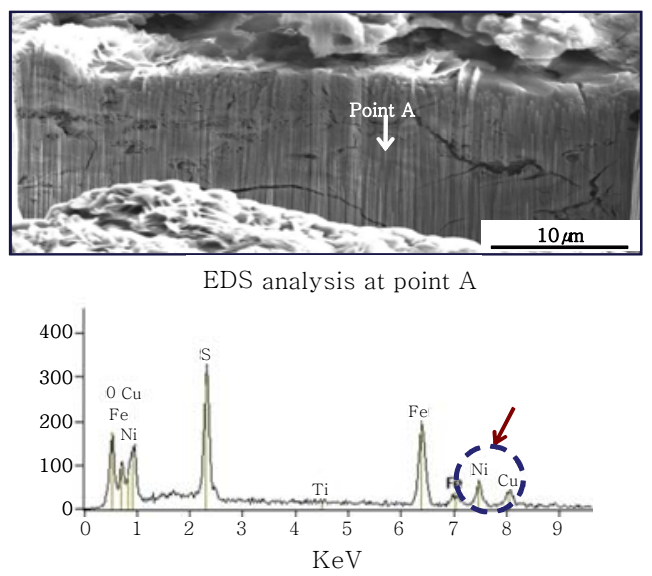

(a)

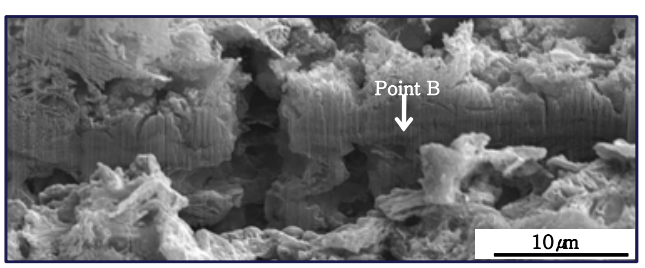

EDS analysis at point B

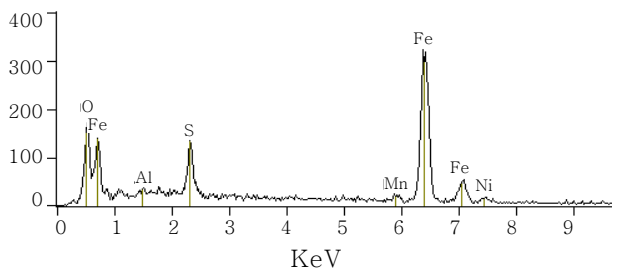

(b)

Fig. 4 Cross $^{-}$sectional morphology of iron sulfide film formed on (a) $\mathrm{Cu}$ and $\mathrm{Ni}$ bearing pressure vessel steel and (b) conventional pressure vessel steel, and EDS analysis on the sulfide film

They have also demonstrated that the $\mathrm{Cu}$ and $\mathrm{Ni}$ bearing steel is more resistant to $\mathrm{HIC}$, which is mainly attributed to the decrease in diffusible hydrogen introduced in the steel.

\section{Effect of tensile stress on hydrogen diffusion}

As indicated above, the HAC phenomenon appears predominantly in the suspectible microstructure and the residual tensile stress caused by the thermal contraction during the welding process $^{24-25)}$. In this regard, since 1970s, the effect of tensile stress on hydrogen permeation through various steels has been extensively investigated ${ }^{26-30)}$. For this, the hydrogen permeation test was conducted utilizing a modified 
Devanathan and Stachurski cell ${ }^{28)}$ equipped with a constant load testing device, so that the specimen is subjected simultaneously to the hydrogen charging and straining during the permeation test. Since Bastien et al. ${ }^{26)}$ suggested that mobile dislocations generated by plastic deformation may carry hydrogen atom in the form of Cottrell atmospheres, the role of plastic deformation on hydrogen transport has been the important subject of numerous theoretical and experimental studies. Kurkela et al. ${ }^{27)}$ have also reported that mobile dislocations carry hydrogen atoms and they have found an increase in the apparent diffusivity of hydrogen by up to 5 orders of magnitude for $\mathrm{Ni}$. On the contrary, the permeation experiments conducted by Kurkela et al. ${ }^{28)}$ with a bainitic $2.25 \mathrm{Cr}-1 \mathrm{Mo}$ steel, and by Zakroczymski et al. ${ }^{29)}$ with pure iron have indicated that dislocation acts as trap for hydrogen atom and therefore the significant decrease in permeation current at the onset of plastic deformation has been observed. Fig. 5 presents the hydrogen permeation transients under three different mechanical domains; generalized elasticity, local-plasticity and generalized plasticity. It is found from the Fig. 5 that the permeation flux increases under the tensile stress in generalized-elastic range, which is due mainly to the lattice expansion. On the contrary, slower diffusion and longer break-through time are observed in the steel under the tensile stress in local/generalized-plastic range. This can be

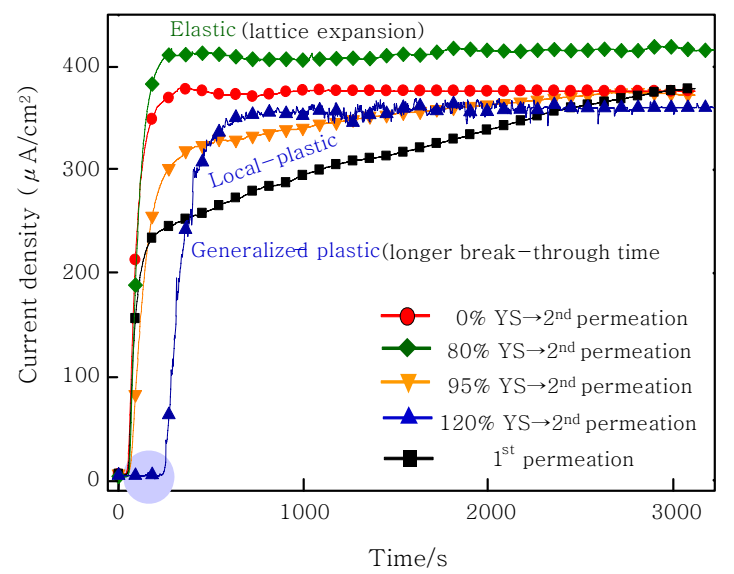

Fig. 5 Hydrogen permeation transients under various tensile stresses in both elastic and plastic ranges explained by the fact that the plastically deformed steel contains a considerable number of dislocations acting as reversible trapping site for hydrogen atoms, and the hydrogen atoms could be additionally trapped at the expanded interfacial gap between the steel matrix $/ 2^{\text {nd }}$ phase particles under the stress condition. Huang et al. ${ }^{3)}$ have also shown that the hydrogen diffusivity decreased as the plastic deformation increased in the static deformation experiments with pure iron, suggesting that hydrogen atoms diffusing in the steel membrane are trapped at dislocations and thus it takes longer time for hydrogen atoms to diffuse out of the steel. Kurkela et al. ${ }^{28)}$ have reported that the contradictory results are attributed to the difference of the binding energy between hydrogen and dislocation in materials. According to them, the binding energy of hydrogen atom to dislocations in BCC alloys is several times higher than that in FCC alloys and thus the dislocations in BCC alloys generated by plastic deformation enhance hydrogen trapping rather than transport, leading to decrease in the apparent diffusivity of hydrogen. Contrary to the plastic tensile stress, tensile stress in elastic range is not supposed to increase the concentration of trap for hydrogen atom and it is known that the apparent diffusion coefficient remains quite constant but the permeation flux increases slightly due mainly to the lattice expansion $^{2,3)}$. Since the lattice parameters of the steel are reversibly enlarged, it can accommodate more hydrogen interstitially. Park et al. ${ }^{5}$ has shown the effect of elastic deformation on hydrogen permeation of API X65 grade linepipe steel. Townsend et al. ${ }^{30}$ have also proposed that the increase in the permeation rate under the loading condition is ascribed to the increase in the exchange current density for the hydrogen reduction reaction on the steel surface even under elastic tensile stress. However, it has not been experimentally demonstrated.

With the experimental studies, theoretical models describing the hydrogen diffusion behavior in the steel membrane have been proposed ${ }^{31-35)}$. In 1963, McNabb and Foster have presented the 
hydrogen diffusion with trapping model, assuming that irreversible trapping sites are not present in the steel matrix ${ }^{31)}$. Oriani et al. ${ }^{32)}$ have developed a solution of McNabb and Foster's model for the case of rapid equilibrium between the trapping and normal diffusion sites. Iino et al. ${ }^{33)}$ have proposed a diffusion model, considering the situation of irreversible trapping. Turnbull et al. ${ }^{34)}$ have conducted a mathematical analysis for hydrogen diffusion in the steel and proposed a numerical solution even in the presence of irreversible traps with a finite trapping rate, not in local equilibrium. On the contrary, CastañoRivera et al. $^{35)}$ have developed a numerical finite difference method (FDM) to solve the diffusion equation under the case of local equilibrium and high fraction of occupied traps with high binding energy. These diffusion models have contributed to figure out the mechanism of HIC failure which is considered as one of the major technical issues for development of high-strength pipe steels used in sour environment. However, there has been no accurate model and equation which can be applied for the real engineering situation where the steel is subjected simultaneously to the hydrogen charging and loading. For this reason, the study on SSC phenomena has not been progressed any further. Especially, under the high level of tensile stress which causes the local plasticity or plastic deformation in the steel, the conventional diffusion equations cannot simulate adequately the experimental results. Since the high level of tensile stress not only generates dislocations but also creates micro-voids or cracks, the hydrogen diffusion and trapping process can be changed significantly. In order to understand clearly the influence of the tensile stress in elastic and plastic range on the hydrogen diffusion process which changes dynamically depending on the trapping property of various types of defects, Kim et al. ${ }^{2)}$ have proposed a numerical model applicable under the stress conditions. According to their study, under high level of tensile stress inducing the local/ generalized plasticity, two kinds of combined effect of the additional hydrogen trapping at expanded interfacial gap between the matrix and $2^{\text {nd }}$ phase particles, and the formation of blister cracks in hydrogen charging side should be considered.

\section{Summary}

This study presents a brief review of corrosion and hydrogen diffusion behaviors of the pipe steel in sour environment. With the depletion of high quality oil and gas, the HAC failure may become serious engineering problem for the high-strength steel pipes due to the poisoning effect by $\mathrm{H}_{2} \mathrm{~S}$. Particularly, the atomic hydrogens which are reduced from $\mathrm{H}^{+}$ions dissociated from $\mathrm{H}_{2} \mathrm{~S}$ are easily adsorbed on the steel surface and diffused into the steel matrix, often resulting in the HAC failure. This hydrogen adsorption and diffusion mechanism suggested by several researchers is introduced. In addition, the iron sulfide film precipitated as a result of electro + chemical corrosion reaction on the steel surface can act not only as a barrier against the hydrogen diffusion but also as sites for the hydrogen reduction reaction. The effect of sulfide film on subsequent hydrogen diffusion and resultant cracking problem is also discussed. Lastly, the influence of tensile stress on hydrogen diffusion and trapping is briefly reviewed based on a number of experimental permeation data and theoretical models describing the hydrogen diffusion in the steel.

\section{References}

1. K. Kiuchi and R. B. Mclellan : The solubility and diffusivity of hydrogen in well-annealed and deformed iron, Acta Metallurgica, 31 (1983), 961- 984

2. S. J. Kim, D. W. Yun, H. G. Jung and K. Y. Kim : Determination of hydrogen diffusion parameters of ferritic steel from electrochemical permeation measurement under tensile loads, Journal of The Electrochemical Society, 161 (12) (2014), E173-E181

3. Y. Huang, A. Nakajima, A. Nishikata, and T. Tsuru : Effect of mechanical deformation on permeation of 
hydrogen in iron, ISIJ International, 43 (2003), 548-554

4. S. J. Kim, H. G. Jung and K. Y. Kim : Effect of tensile stress in elastic and plastic range on hydrogen permeation of high-strength steel in sour environment, Electrochimica Acta, 78 (2012), 139146

5. G. T. Park, S. U. Koh, H. G. Jung and K. Y. Kim : Effect of microstructure on the hydrogen trapping efficiency and hydrogen induced cracking of linepipe steel, Corrosion Science 50 (2008), 1865-1871

6. H. - Y. Liou, R. - I. Shieh, F. - I. Wei and S. -C. Wang : Roles of microalloying elements in hydrogen induced cracking resistant property of HSLA steels, Corrosion, 49 (1993) 389-398

7. C. Mendibide and T. Sourmail : Composition optimization of high-strength steels for sulfide stress cracking resistance, Corrosion Science, 51 (2009), 2878-2884

8. W. K. Kim, H. G. Jung, G. T. Park, S. U. Goh and K. Y. Kim, Relationship between hydrogen-induced cracking and type I sulfide stress cracking of highstrength linepipe steel, Scripta Materialia 62 (2010), 195-198

9. P. G. Kumar and K. Yu-ichi : Diffusible hydrogen in steel weldments, Transactions of JWRI 42 (2013), 39-62

10. S. J. Kim, H. G. Jung, G. T. Park and K. Y. Kim : Effect of $\mathrm{Cu}$ and $\mathrm{Ni}$ on sulfide film formation and corrosion behavior of pressure vessel steel in acid sour environment, Applied Surface Science 313 (2014) 396-404

11. J. O'M. Bockris, J. McBreen and L. Nanis : The hydrogen evolution kinetics and hydrogen entry into a-iron, Journal of Electrochemical Society, 112 (1965), 1025-1031

12. P. W. Bolmer : Polarization of Iron in $\mathrm{H}_{2} \mathrm{~S}-\mathrm{NaHS}$ Buffers, Corrosion, 21 (1965), 69-75

13. Z. A. Iofa and F. L. Kam : Protection of metal, Zashchita Metallov, 10 (1974) 17

14. A. Kawashima, K. Hashimoto and S. Shimodaira : Hydrogen electrode reaction and hydrogen embrittlement of mild steel in hydrogen sulfide solutions, Corrosion, 32 (1976), 321-332

15. Y. T. He, J. T. Wilson and R. T. Wilkin : Impact of iron sulfide transformation on trichloroethylene degradation, Geochimica et Cosmochimica Acta. 74 (2010), 2025-2039.

16. H. Kobayashi, T. Nozue, T. Matsumura and T. Suzuki : The low-temperature specific heat of FeS and $\mathrm{M}_{0.875} \mathrm{X}(\mathrm{M}=\mathrm{Fe}, \mathrm{Co} ; \mathrm{X}=\mathrm{S}$, Se) with a NiAs-like structure, Journal of Physics-Condensed Matter, 11 (1999), 8673-8679

17. NACE standard TM0284 : Evaluation of pipeline and pressure vessel steels for resistance to hydrogen induced cracking, NACE International,
Houston, TX (2003)

18. H. Inagaki, M. Tanimura, I. Matsushima and T. Nishimura : Effect of $\mathrm{Cu}$ on the hydrogen induced cracking of the pipe line steel, ISIJ International, 18 (1978), 149-156

19. R. A. Carneiro, R. C. Ratnapuli and V. d. F. C. Lins : The influence of chemical composition and microstructure of API linepipe steels on hydrogen induced cracking and sulfide stress corrosion cracking, Materials Science and Engineering, A357 (2003), 104-110

20. R. Blondeau : Problems related to use of low apply steels in $\mathrm{H}_{2} \mathrm{~S}$ environments, Ironmak. Steelmak. 18 (3) (1991), 201-210

21. G. M. Waid and R.T. Ault : The development of high strength casing steels with improved hydrogen sulfide cracking resistance for sour service, Proceedings of the NACE International Conference, Colorado Springs, USA, (1979)

22. G. C. Schmid : The resistance of nickel containing ssteels and weld metals to sulphide stress corrosion cracking, Proceedings of the NACE International Conference, Colorado Springs, USA, (1979)

23. B. E. Wilde, C. D. Kim and J. C. Turn : The influence of noble metal additions on the sulfide corrosion performance of AISI 4130 steel, Corrosion, 38 (1982), 515-524

24. J. S. Yoo, G. Xian, M. J. Lee, Y. D. Kim, N. H. Kang : Hydrogen embrittlement resistance and diffusible hydrogen desorption behavior of multipass FCA weld metals, Journal of the Korean Welding and Joining Society, 31 (2013) 112-118.

25. D. Y. Kim, I. S. Hwang, D. C. Kim, M. J. Kang : Effect of preheat temperature on diffusible hydrogen content in weld metal deposited using flux cored wire, Journal of welding and joining, 32 (2014) $18-21$

26. P. Bastien and P. Azou : Influence de L' croussage Sur le Frottement Inttirieur du Fer et de L'ancior, C. R. Academy of Sciences at Paris. 232 (1951) 1845-1848

27. M. Kurkela and R. M. Latanision : The effect of plastic deformation on the transport of hydrogen in nickel, Scripta Metallurgica, 13 (1979), 927-932

28. M. Kurkela, G. S. Frankel, R. M. Latanision, S. Suresh and R. O. Ritchie : Influence of plastic deformation on hydrogen transport in $2.25 \mathrm{Cr}-1 \mathrm{Mo}$ steel, Scripta Metallurgica, 16 (1982), 455-459

29. T. Zakroczymski : The effect of straining on the transport of hydrogen in iron and stainless steel, Corrosion, 41 (1985) 485-489

30. H. E. Townsend : Effects of stress on entry and permeation of hydrogen in iron, Corrosion, 26 (1970), 361-362

31. A. McNabb and P. K. Foster : A new analysis of the diffusion of hydrogen in iron and ferritic steels, 
Transactions of the Metallurgical Society of A.I.M.E. 227 (1963), 618-627

32. R. A. Oriani : The diffusion and trapping of hydrogen in steel, Acta Metallurgica, 18 (1970), 147-157

33. M. Iino : A more generalised analysis of hydrogen trapping, Acta Metallurgica, 30 (1982) 367-375

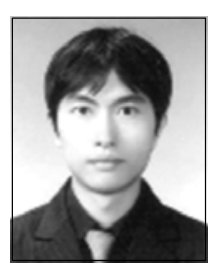

Sung Jin Kim Sung Jin Kim graduated from pohang university of science and technology (POSTECH) for B.S in Industrial engineering, M.S and Ph.D in Ferrous Technology.

$\mathrm{He}$ is working at welding and joining research group in POSCO as a senior researcher. His current research interests include corrosion, and welding science and technology.
34. A. Turnbull, M. W. Carroll and D. H. Ferriss : Analysis of hydrogen diffusion and trapping in a $13 \%$ chromium martensitic stainless steel, Acta Metallurgica, 37 (1989) 2039-2046

35. P. Castaño-Rivera, V. P. Ramunni and P. Bruzzoni : Hydrogen trapping in an API 5L X60 steel, Corrosion Science, 54 (2012) 106-118

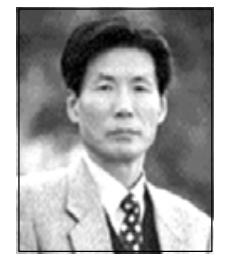

Kyoo Young Kim graduated from Polytechnic Institute of Brooklyn for B.S in Metallurgical Engineering, and has got his Ph.D from the university of Connecticut in Materials Science and Engineering.

Professor Kim is working at pohang university of science and technology (POSTECH) for more than 25 years, educating and researching in the corrosion sicence and technology. Professor Kim is one of the leading scientists in the field of electrochemical corrosion and hydrogen assisted cracking of metallic materials. 